Article

\title{
Cavitation Damage Prediction of Stainless Steels Using an Artificial Neural Network Approach
}

\author{
Guiyan Gao ${ }^{1}$, Zheng Zhang ${ }^{1,2, *}$, Cheng Cai ${ }^{1,2}$, Jianglong Zhang ${ }^{3} \odot$ and Baohua Nie ${ }^{4}$ \\ 1 Institute of Failure Analysis and Prevention, School of Materials Science and Engineering, Beijing University \\ of Aeronautics and Astronautics, Beijing 100191, China; gaogy@buaa.edu.cn (G.G.); \\ buaamsecc@163.com (C.C.) \\ 2 The Collaborative Innovation Center for Advanced Aero-Engine, Beijing University of Aeronautics and \\ Astronautics, Beijing 100191, China \\ 3 Shen Yuan Honors College, Beijing University of Aeronautics and Astronautics, Beijing 100191, China; \\ zhangj11330@buaa.edu.cn \\ 4 School of Material Science and Energy Engineering, Foshan University, Foshan 528000, China; \\ niebaohua121@163.com \\ * Correspondence: zhangzh@buaa.edu.cn; Tel.: +86-136-0102-3762
}

Received: 1 April 2019; Accepted: 22 April 2019; Published: 30 April 2019

\begin{abstract}
Cavitation damage has not been well predicted because of its complex relationship of many mechanical and microstructural factors. An artificial neural network approach of the back-propagation network was used to predict cavitation damage of stainless steels, 316L and 420, in terms of the significant influence of cavitation time, roughness, and residual stress on cavitation damage. Mean depth of erosion was used to quantitatively describe cavitation damage of 316L and 420. Prediction accuracy was improved by analyzing the effects of the number and type of input nodes, the number of nodes in the hidden layer, and different activation functions on prediction accuracy. The best performance was in the model with the input nodes of cavitation time and roughness, eleven nodes in the hidden layer, and the activation function of logsig.
\end{abstract}

Keywords: artificial neural network; cavitation damage; residual stress

\section{Introduction}

Cavitation erosion (CE) is a kind of damage where cavitation bubbles that form in the liquid collapse near the solid boundary, which results in erosion from micro jets and shock waves [1-3]. It often leads to severe equipment damage of hydraulic machinery such as pumps, turbines, valves, pipes, vessels, and so on [1,4]. Cavitation damage has been modeled previously $[1,5,6]$. Szkodo [7] introduced an evaluation of cavitation damage, where they compared CE curves with a Weibull distribution, considering the influence of plastic deformation and the stress intensity factor, and they gave a mathematical model. Shuji et al. [8,9] analyzed characterization of the erosion process. They assumed the damage as pits and then formulated cavitation erosion depth; however, the quantitative accuracy and verification of their formulations were not shown. It has been found that cavitation erosion behavior was related to microstructure and mechanical properties of materials [10-14]. Multiple mechanical parameters affect $\mathrm{CE}$, such as yield strength, ultimate strength, hardness, toughness, fracture toughness, and work-hardening capacity, and are considered to be correlated with cavitation erosion behavior [13-16]. There are arguments, especially about the effect of hardness on CE [15,17]. CE is viewed as a fatigue process $[18,19]$. Residual stress and roughness, which influence the fatigue behavior of materials [20-22], may affect the cavitation erosion behavior of materials. It can be seen that the evolution of cavitation damage is nonlinear and complex; it is difficult to build accurate equations 
for cavitation damage. Therefore, an artificial neural network (ANN) method is introduced to evaluate cavitation damage.

ANN is inspired by the biological nervous system. It is suitable to manage engineering problems that are complicated and difficult to formulate $[23,24]$. ANN is often utilized to quantitatively predict and identify damage. Jeyasehar and Sumangala [24] utilized back-propagation ANN to assess damage in prestressed concrete beams. They found there was a strong dependence of the natural frequency, defection, crack load, crack width and ultimate load on the damage levels of the beams, and that the ANN prediction model trained with applied load and natural frequency on the prestressed concrete beams can be less than 10\% error. Ye et al. [25] used ANN to predict damage presence and the location of composite. They reduced computational time and effort in obtaining the training database by adopting a hierarchical approach. Zang and Imregun [26] used the ANN approach and input data from measured frequency response functions to detect structural damage. They reduced data by using the principal component analysis. Strdczkiewicz and Barszcz [27] applied back-propagation ANN in damage detection of the planetary gearbox of a wind turbine.

During modeling, firstly, an appropriate network should be selected and modeled. A large amount of input and output data are needed to train the network. The weights can be voluntarily adjusted according to the selected learning algorithm until the error is less than the acceptable limit [28]. Then, the trained network can be utilized for the applications. It is important for the model to select the appropriate learning algorithm, activation function, and architecture, according to the characteristics of ANN and cavitation damage prediction. Altarazi et al. [29] used the ANN to evaluate and optimize the properties of extruded polyvinylchloride composites. They obtained an accurate prediction model by comparing model errors of different learning algorithms, activation functions, and architectures. Thus, an accurate prediction of cavitation damage may be achieved by using the ANN method.

As CE is correlated to microstructure and mechanical properties of materials, materials with distinguished microstructures should be considered during the modeling of cavitation damage. Austenite 316L and martensite 420 are typical stainless steels applied in the hydraulic industry because of their good mechanical properties and corrosion resistances [30]. The aim of this paper is to utilize a suitable artificial neural network to predict the cavitation damage of stainless steels, in terms of microstructural and mechanical parameters affecting the cavitation damage of stainless steels. This work may be helpful in failure analysis and prevention in hydraulic machinery components.

\section{Experiments}

\subsection{Experimental Program}

The cavitation erosion test was conducted by using a modified ultrasonic fatigue apparatus according to ASTM G32-03 [31]. Cavitation bubbles were produced under a vibrating tip. The frequency of vibration was $20 \pm 0.2 \mathrm{kHz}$. The peak-to-peak amplitude was $50 \pm 0.6 \mu \mathrm{m}$. The vibrating tip was made of Ti-6Al-4V. The vibrating tip was immersed about $4 \mathrm{~mm}$ in tap water. The test was performed in running water with a stationary specimen method, as the stationary specimen method was convenient for characterizing eroded specimens. The standoff distance between specimen and tip was $0.5 \mathrm{~mm}$. The specimen was placed under the vibrating tip. The vibrating tip introduced cavitation bubbles, the cavitation bubbles collapsed close to the specimens, and then specimens were eroded by the cavitation bubbles. The schematic image of the machine is shown in Figure 1. The temperature around the stationary specimen was kept at $25 \pm 3{ }^{\circ} \mathrm{C}$. As-received 420 and $316 \mathrm{~L}$ were chosen as tested materials, their chemical compositions and mechanical properties are listed in Tables 1 and 2, respectively. Specimens $(20 \mathrm{~mm} \times 20 \mathrm{~mm} \times 10 \mathrm{~mm})$ were made using wire electrical discharge machining. Specimens were ground and polished before they were taken to the cavitation erosion test. After the test, specimens were cleaned and dried by hot air, then the mass loss of the materials was weighed by an electronic balance with an accuracy of $0.1 \mathrm{mg}$. The eroded surfaces of specimens after different cavitation times are shown in Figure 2. For characterization, residual stress measurements 
were conducted on the eroded surface via X-ray diffraction. Three points were tested at different distances from the erosion center $(0,2$, and $4 \mathrm{~mm})$, then the average values and errors were calculated. Roughness was measured by a roughness measuring instrument. The microhardness test was carried out on a cross-section of the eroded specimen using a Vickers microhardness tester under loads of $100 \mathrm{gf}$ and $200 \mathrm{gf}$ for 316L and 420, respectively, with a dwell time of $15 \mathrm{~s}$. The tested points were about $100 \mu \mathrm{m}$ from the eroded surface.

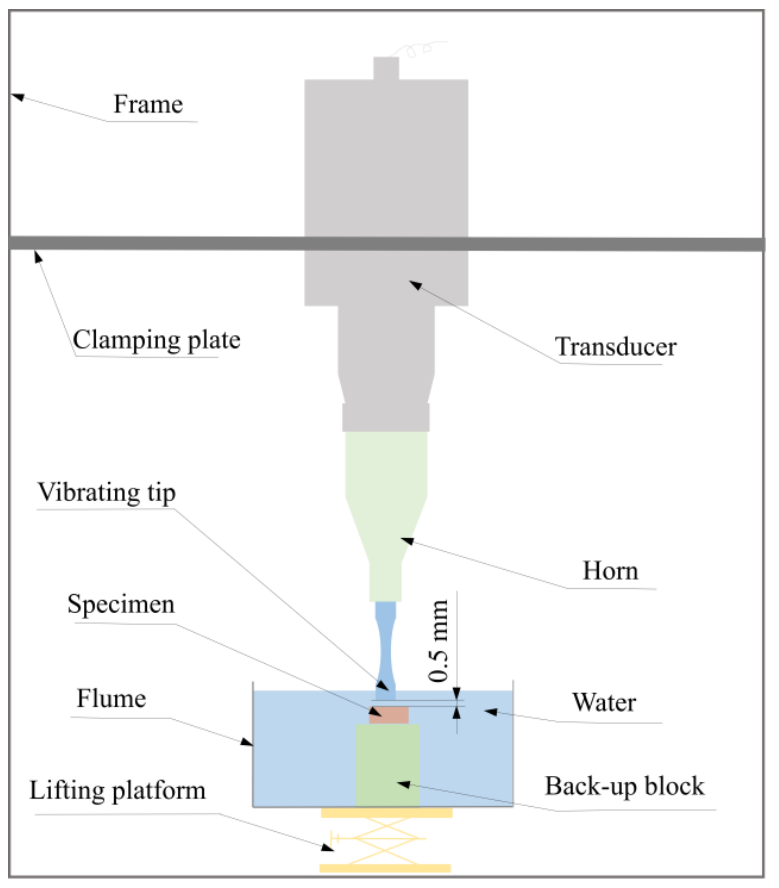

(a)

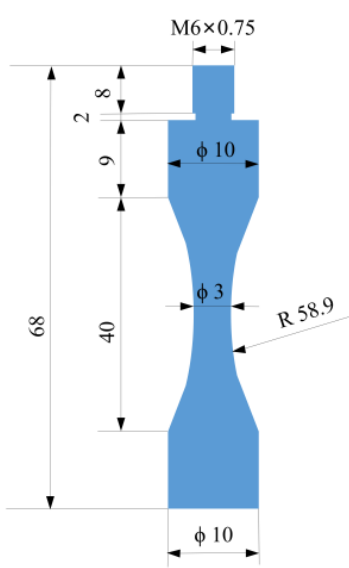

(b)

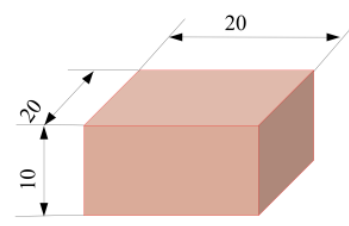

(c)

Figure 1. (a) Schematic image of the machine, (b) shape and size of the vibrating tip, and (c) shape and size of the specimen. (Unit: $\mathrm{mm}$ ).

Table 1. Chemical compositions of 420 and 316L.

\begin{tabular}{ccccccccccc}
\hline \multirow{2}{*}{ Material } & \multicolumn{10}{c}{ Chemical Composition } \\
\cline { 2 - 11 } & $\mathbf{C}$ & $\mathbf{C r}$ & Ni & Mn & Si & Mo & $\mathbf{P}$ & S & N & Fe \\
\hline 420 & 0.20 & 12.10 & 0.28 & 0.34 & 0.29 & - & 0.026 & 0.015 & - & Bal. \\
\hline $316 \mathrm{~L}$ & 0.019 & 16.96 & 10.52 & 0.95 & 0.37 & 2.14 & 0.045 & 0.0027 & 0.036 & Bal. \\
\hline
\end{tabular}

Table 2. Mechanical properties of 420 and 316L.

\begin{tabular}{|c|c|c|c|c|}
\hline Material & $\begin{array}{c}\text { Yield Strength } \\
\sigma_{0.2}(\mathrm{MPa})\end{array}$ & $\begin{array}{c}\text { Tensile Strength } \\
\text { (MPa) }\end{array}$ & $\begin{array}{c}\text { Vickers } \\
\text { Microhardness (HV) }\end{array}$ & Density $\left(\mathrm{g} / \mathrm{cm}^{3}\right)$ \\
\hline 420 & 536 & 705 & 185 & 7.85 \\
\hline $316 \mathrm{~L}$ & 401 & 651 & 152 & 7.98 \\
\hline
\end{tabular}




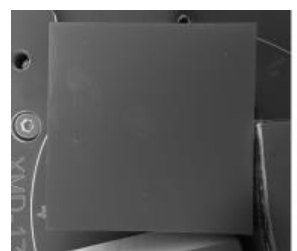

(a)

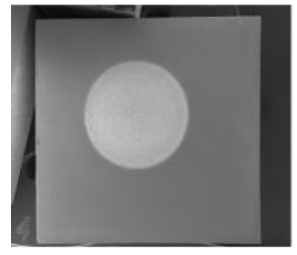

(d)

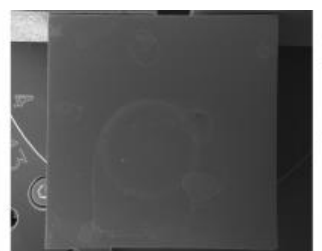

(b)

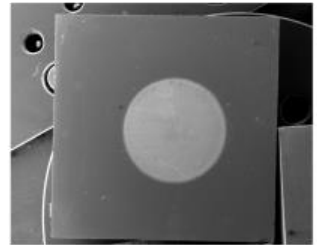

(e)

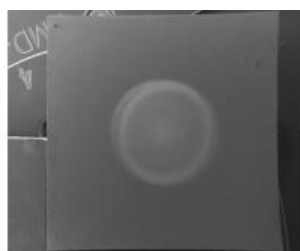

(c)

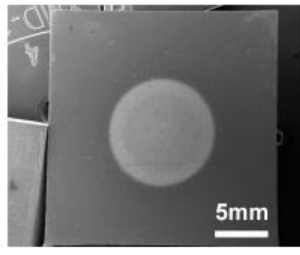

(f)

Figure 2. Eroded surfaces of specimens of 420 after different cavitation times: (a) $10 \mathrm{~min}$, (b) $30 \mathrm{~min}$, (c) $60 \mathrm{~min},(\mathrm{~d}) 120 \mathrm{~min},(\mathbf{e}) 180 \mathrm{~min}$, and (f) $240 \mathrm{~min}$.

In order to quantitatively study the relationship between cavitation damage and the parameters of cavitation time, roughness, residual stress, and microhardness, the mean depth of erosion (MDE) was used to describe cavitation damage, and it was calculated by using the following equation:

$$
\mathrm{MDE}=\frac{1000 \Delta m}{\rho A},
$$

where $\Delta m$ is the mass loss ( $\mathrm{mg}), \rho$ is the density of the materials $\left(\mathrm{mg} / \mathrm{mm}^{3}\right)$, and $A$ is the area of eroded surface $\left(\mathrm{mm}^{2}\right)$.

\subsection{Significant Parameters of Cavitation Damage}

The relationship between cavitation damage (mean depth of erosion) and cavitation time for 316L and 420 is presented in Figure 3a. In general, the cavitation damage of $316 \mathrm{~L}$ and 420 increased with cavitation time. The cavitation damage evolution of $316 \mathrm{~L}$ was similar to that of 420 . The relationship between cavitation damage and average roughness of the eroded surface of $316 \mathrm{~L}$ and 420 is presented in Figure $3 b$. Roughness increased with cavitation time because cavitation damage became increasingly serious; this was also found locally in other cavitation erosion processes [32-35]. On the whole, cavitation damage was proportional to roughness. The evolution rate of cavitation damage of 420 with roughness was faster than that of 316L. The relationship between cavitation damage and hardness of 316L and 420 is shown in Figure 3c. Because of the non-monotonic relationship between hardness and cavitation damage, especially for 316L, cavitation damage was not directly connected to hardness. The relationship between cavitation damage and residual stress is displayed in Figure 3d. It can be found that the residual stress of 316L was lower than that of 420 during CE. Meanwhile, cavitation damage of 316L and 420 increased overall with residual stress. 


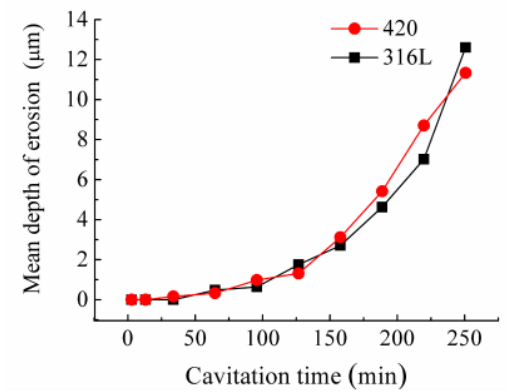

(a)

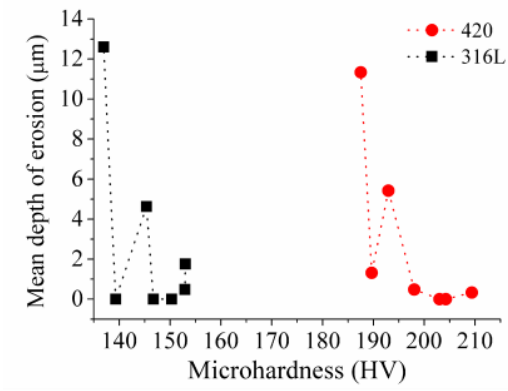

(c)

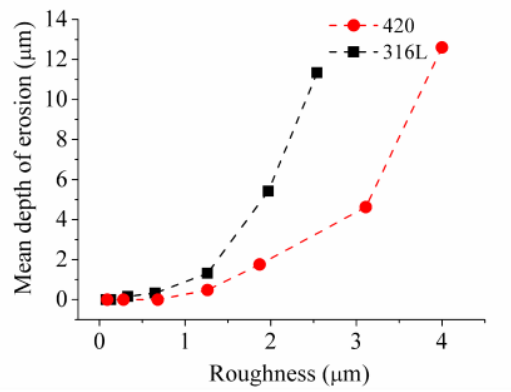

(b)

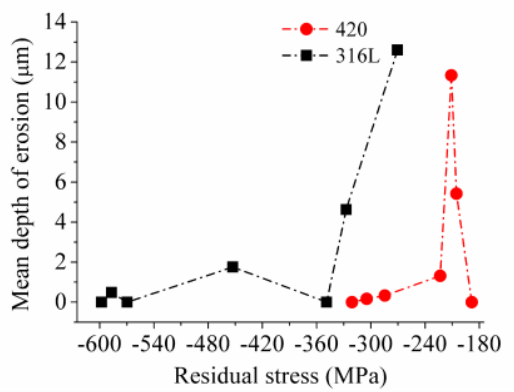

(d)

Figure 3. (a) Cavitation time, (b) roughness, (c) microhardness, and (d) residual stress as a function of the mean depth of erosion of 420 and 316L.

\section{Artificial Neural Network (ANN) Approach}

\subsection{Back-Propagation Neural Network}

ANN is an algorithmic, mathematical model for distributed, parallel information processing. It adjusts connections between a large number of internal nodes, according to the complexity of the system, to achieve the purpose of processing information. ANN has the ability of self-learning and self-adaptation. Back-propagation (BP) neural network is a kind of supervised feed-forward neural network. The processing units in the BP neural network include input layer, output layer, and several hidden layers. Units in the hidden layer are used to compute the weights between pattern, the error between generated output, and the targeted output is fed backward to modify its weight [24]. BP is widely applied because it is able to deal with complex, nonlinear mapping. It is particularly suitable for solving complex problems with internal mechanisms. Therefore, BP was adopted in this paper.

$B P$ requires that the activation function used by the artificial nodes be differentiable, thus, logsig and tansig were utilized as the activation functions in the hidden layer. The activation function of purelin was used by default in the output layer. Although the result of the Levenberg-Marquardt training approach may be trapped in the local optima [23], needing larger storage space than other training algorithms, application of the Levenberg-Marquardt training approach in BP usually gets better results than other training algorithms, and its convergence rate is fast; thus, it is often applied.

\subsection{Damage Prediction Using ANN}

Parameters that influenced cavitation damage were used as the network input nodes, and the mean depth of erosion was used as the output. Besides the input and output layers, the hidden layer was included in BP. Generally, one or more layers could be utilized as hidden layers in the BP neural network. As there were not many input and output nodes, and one hidden layer was used in many applications with a desired accuracy [36], one hidden layer was adopted in this work. The number of hidden nodes could be estimated by Kolmogorov's theorem [37],

$$
N_{\mathrm{h}}=2 N_{\mathrm{i}}+1,
$$


where $N_{\mathrm{i}}$ is the number of input nodes, and $N_{\mathrm{h}}$ is the number of hidden nodes. Then, the number of layers and the number of the nodes of each layer were confirmed.

As surface roughness and residual stress were related to cavitation damage, cavitation time affected the damage as well. Therefore, cavitation time, roughness, and residual stress could be used as input nodes, namely, the largest of the number of input nodes $N_{\mathrm{i}}$ could be set as 3, and $N_{\mathrm{h}}$ could be set as 7 according to the Equation (2). The mean depth of erosion represented the output node, namely, there was one output in the network, as is shown in Figure 4. The linear interpolation method was used to obtain enough instances from the tested data. There were 48 sets of data for inputs and outputs. Among those data, 42 groups of instances were selected randomly to model the network, 26 (about 60\%) instances were used for training, 8 (about 20\%) for validation, and the other 8 for testing the network. Besides, the remaining six instances were used to test the network model. The ANN architecture of three input nodes is shown in Figure 4.

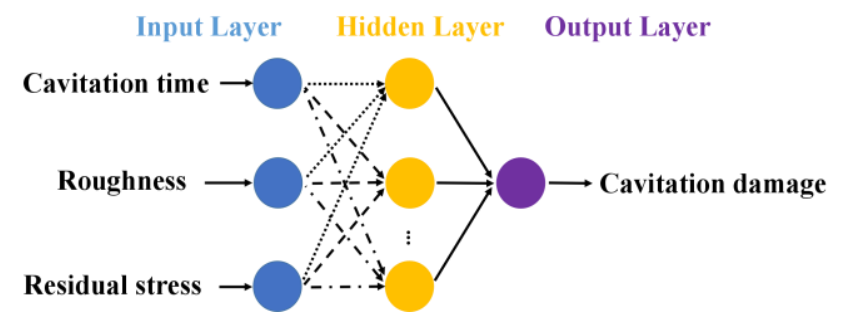

Figure 4. Structure for models with the input nodes of cavitation time, roughness, and residual stress $(T \& R \& S)$.

Initial data of the connection weight coefficients of the layers were given by random numbers. Training was terminated when the average squared error between the network output and the target output was less than 0.00001 . The maximum number of epochs was set as 500 , and the learning rate was set as 0.05 . The algorithm was written in MATLAB. The Neural Network toolbox was utilized to define, train, and simulate the network model. The built network model was repeated 50 times to check prediction accuracy and capability. To determine the performance of the network model, three different criteria were used: the relative absolute mean error (RAME), the root mean square error (RMSE), and the coefficient of determination $\left(R^{2}\right)[29,38]$. The equations of these criteria are as follows:

$$
\begin{gathered}
\text { RAME }=\frac{1}{n} \sum_{i=1}^{n}\left|\frac{y_{\mathrm{p} i}-y_{i}}{y_{\mathrm{p} i}}\right|, \\
\operatorname{RMSE}=\sqrt{\frac{\sum_{i=1}^{n}\left(y_{\mathrm{p} i}-y_{i}\right)^{2}}{n}}, \\
R^{2}=\left(\frac{n \sum_{i=1}^{n} y_{i} y_{\mathrm{p} i}-\sum_{i=1}^{n} y_{i} \sum_{i=1}^{n} y_{\mathrm{p} i}}{\sqrt{n \sum_{i=1}^{n} y_{i}^{2}-\left(\sum_{i=1}^{n} y_{i}\right)^{2}} \sqrt{n \sum_{i=1}^{n} y_{\mathrm{p} i}^{2}-\left(\sum_{i=1}^{n} y_{\mathrm{p} i}\right)^{2}}}\right)^{2},
\end{gathered}
$$

where $y_{\mathrm{p} i}$ is the predicted value, $y_{i}$ is the target value, and $n$ is the number of instances. As the mean depth of erosion in the initial stage was zero, thus, the predicted value was used as the denominator of RAME.

\section{Results and Discussion}

As is shown in Figure 3, cavitation time and roughness were proportional to cavitation damage. Cavitation damage could be expressed by the mean depth of erosion according to Equation (1), as residual stress was considered an important factor for cavitation erosion behavior, and it had the 
tendency to increase with the cavitation damage; therefore, cavitation time, roughness, and residual stress were used as input nodes for cavitation damage prediction using ANN. To evaluate and improve the prediction accuracy of the ANN model, the effect of the number and type of input nodes, the number of nodes in the hidden layer, and different activation functions on prediction were analyzed. RAME, RMSE, and $R^{2}$ were considered the evaluation criteria.

\subsection{The Effects of Type and Number of Input Nodes on Prediction}

Figure 5 presents the effect of type and the number of input nodes on cavitation damage prediction for 420 and 316L. The number of nodes in the hidden layer of all models was seven in Figure 5. It seemed that the number of input nodes did not affect prediction results. But for the type of input nodes, it was apparent that the worst performance was in the model with the residual stress input node. This was probably because the value of residual stress was not accurate, as the measurement of residual stress was affected by the roughness of the eroded surface. Relatively good performances were achieved by the model with cavitation time and roughness (T\&R) input nodes and the model with the input node of cavitation time $(T)$. To analyze the best performance of models with different input nodes, RAME, RMSE, and $R^{2}$ values for models with $T \& R$ and $T$ are shown in Table 3. Regardless of the similar criteria results, RAME, $R^{2}$ of the model with 420 , and $R^{2}$ of the model with $316 \mathrm{~L}$ showed that the best performance was achieved by the model with the input nodes of cavitation time and roughness $(T \& R)$, as the prediction model using the input nodes of $T \& R$ had smaller RMSE values.

420

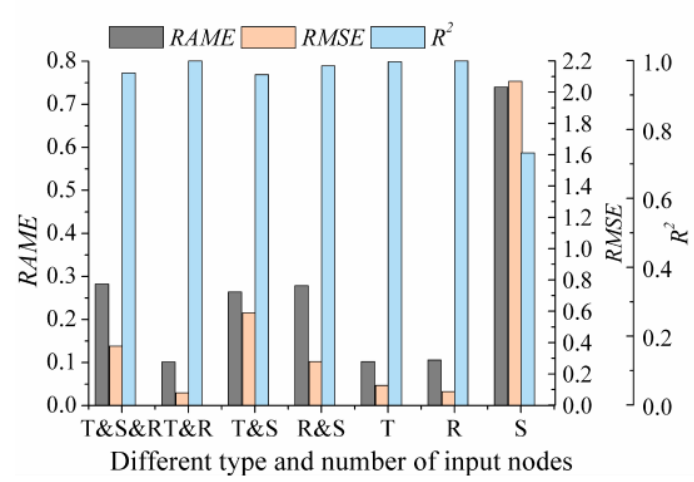

(a)
$316 \mathrm{~L}$

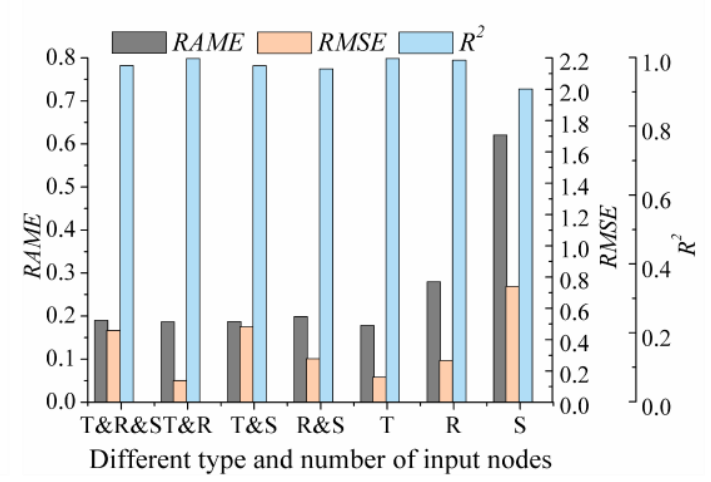

(b)

Figure 5. Relative absolute mean error (RAME), root mean square error (RMSE), and $R^{2}$ for models with different numbers and types of input nodes and different stainless steels (a) 420 and (b) 316L.

Table 3. RAME, RMSE, and $R^{2}$ for the models with input nodes of $T \& R$ and the models with input node of $T$ in Figure 3.

\begin{tabular}{ccccccc}
\hline Stainless Steels & \multicolumn{3}{c}{ 420 } & \multicolumn{3}{c}{ 316L } \\
\hline \multirow{2}{*}{ Input Nodes } & \multicolumn{5}{c}{ Criteria } \\
\cline { 2 - 7 } & RAME & RMSE & $\boldsymbol{R}^{\mathbf{2}}$ & RAME & RMSE & $\boldsymbol{R}^{\mathbf{2}}$ \\
\hline$T \& R$ & 0.1015 & 0.0797 & 0.9990 & 0.1868 & 0.1385 & 0.9968 \\
$T$ & 0.1020 & 0.0866 & 0.9993 & 0.1785 & 0.1616 & 0.9971 \\
\hline
\end{tabular}

\subsection{The Effects of the Number of Nodes in the Hidden Layers on Prediction}

It has been suggested that the number of nodes in the hidden layer influences the results of the ANN model, and that usually the more nodes there are in the hidden layer the better the ANN performance [39]. RAME, RMSE, and $R^{2}$ for different numbers of nodes in the hidden layer and different numbers and types of input nodes are presented in Figure 6. For one input node, the input node of residual stress $(S)$ was not analyzed for its worst performance, shown in Figure 5. In Figure 6a,b 
it was interesting to find that on the whole, for models with input node, cavitation time $(T)$, and roughness $(R)$, the performances of these two models became increasingly worse with the increase of node number in the hidden layer. The best performance was achieved by the model with the input node of cavitation time $(T)$ and seven nodes in the hidden layer, as shown in Figure 6a,b. For models with three and two input nodes, results of their criteria were irregular, as displayed in Figure $6 c, d$. But it could be seen that the best performance was achieved by the model with the input nodes of cavitation time and roughness $(T \& R)$ and eleven nodes in the hidden layer, and that the best performance of models with three input nodes (cavitation time, roughness, and residual stress (T\&R\&S)) was in the model with three nodes in the hidden layer, as shown in Figure 6e,f.

420

Input nodes-Criterion

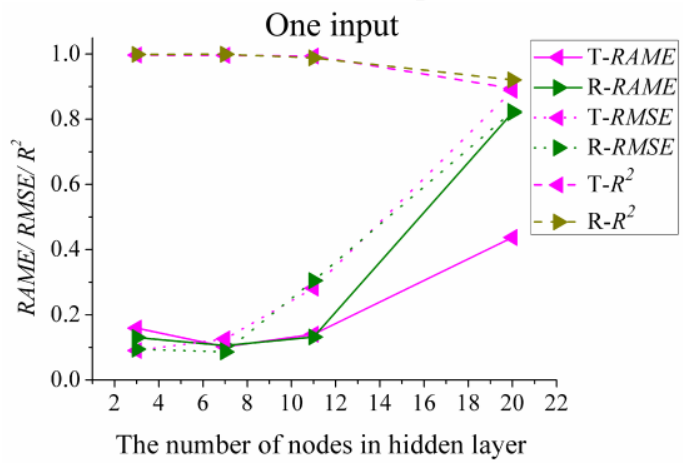

(a)

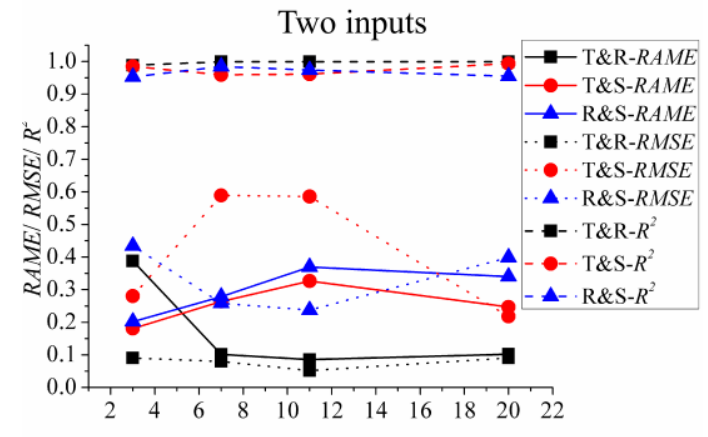

The number of nodes in the hidden layer

(c)

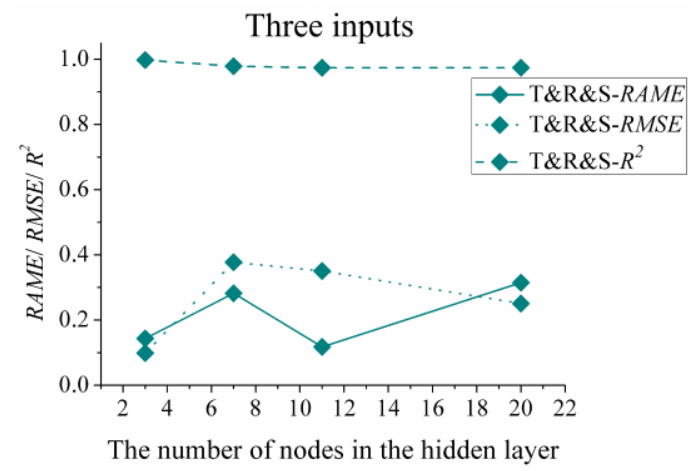

(e)
$316 \mathrm{~L}$

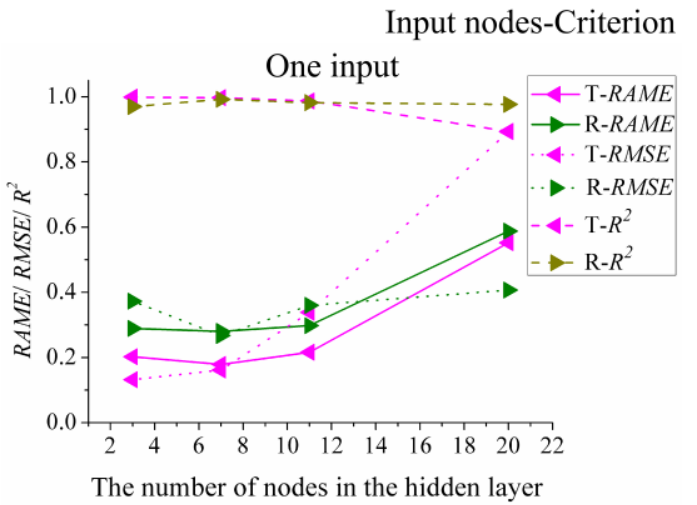

(b)

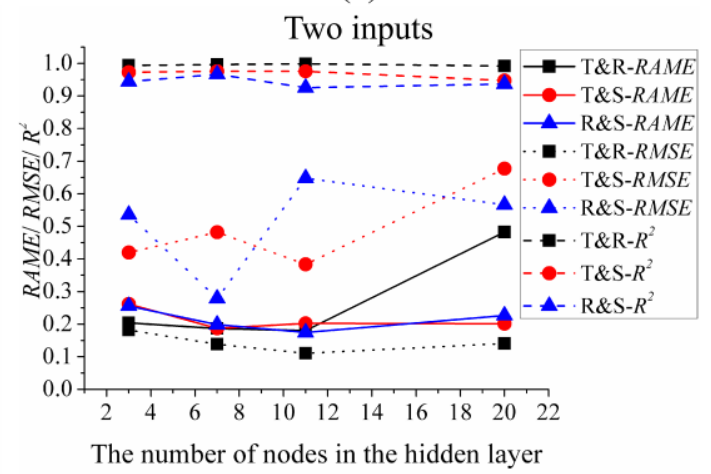

(d)

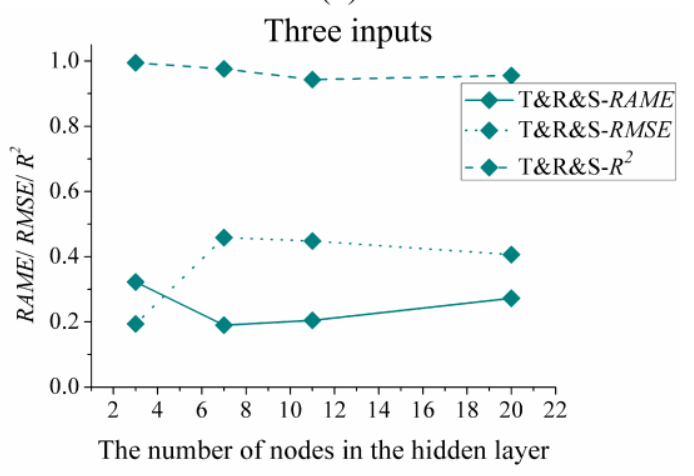

(f)

Figure 6. RAME, RMSE, and $R^{2}$ for models with different numbers of nodes in the hidden layer: $(\mathbf{a}, \mathbf{b})$ one input node, $(\mathbf{c}, \mathbf{d})$ two input nodes, and $(\mathbf{e}, \mathbf{f})$ three input nodes. 


\subsection{The Effects of Activation Functions on Prediction}

From the above analysis it was seen that for the models with three input nodes (cavitation time, roughness, and residual stress $(T \& R \& S)$ ), the best performance was in the model with three nodes in the hidden layer ( $T \& R \& S-3$ ); for the models with two input nodes, the best performance was achieved in the model with the input nodes of cavitation time and roughness and eleven nodes in the hidden layer ( $T \& R-11)$; and for the models with one input node, the best performance was obtained by the model with the input node of cavitation time and seven nodes in the hidden layer (T-7). To further improve the accuracy of prediction, the effect of different activation functions on the prediction is shown in Figure 7. It was drawn that the activation function of logsig could slightly improve the accuracy of prediction. The best performance was in the model with the input nodes of cavitation time and roughness, eleven nodes in the hidden layer, and the activation function of logsig ( $T \& R-11$-logsig) - the criteria results of this model, RAME, RMSE, and $R^{2}$ were about $0.17,0.13$, and 0.999 , respectively.
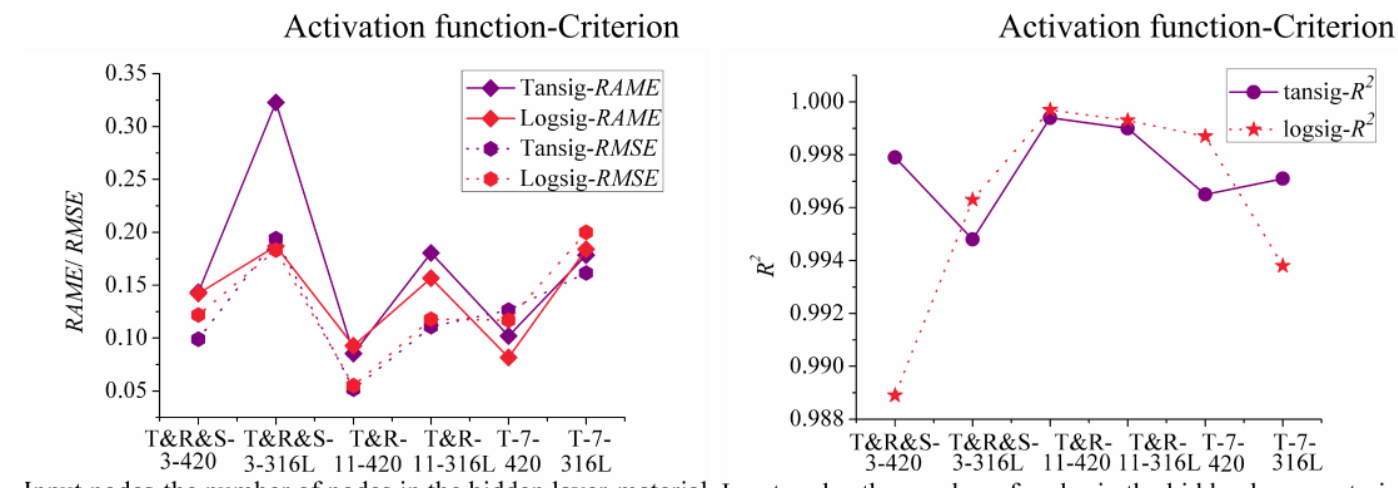

Input nodes-the number of nodes in the hidden layer-material Input nodes-the number of nodes in the hidden layer-material

(a)

(b)

Figure 7. Criteria for models with different activation functions: (a) RAME and RMSE and (b) $R^{2}$.

\section{Conclusions}

In this paper, it can be found that there are relationships between cavitation damage and the parameters including cavitation time, roughness, and residual stress. ANN modeling of cavitation damage of 420 and 316L is investigated based on this relationship, and the following conclusions can be drawn:

(1) A prediction approach using the artificial neural network for the cavitation damage is proposed.

(2) From the analysis of the relationship between cavitation damage and microhardness, microhardness seems not to be related to cavitation damage.

(3) From analysis of the relationship between cavitation damage, residual stress, and the ANN model, residual stress seems not to be related to cavitation damage.

(4) Cavitation damage is affected by cavitation time and roughness. The increase of cavitation time or the increase of roughness during the cavitation erosion process increases cavitation damage.

(5) The model using BP method with input nodes of cavitation time and roughness, eleven nodes in the hidden layer, and the activation function of logsig has a good performance of forecasting cavitation damage.

Author Contributions: G.G. wrote this paper, Z.Z., C.C., J.Z. and B.N. reviewed this paper.

Funding: This work is funded by the National Key Research and Development Program of China, grant number: 2016YFF0203301.

Acknowledgments: The authors would like to thank Luowei Cao from China Special Equipment Inspection and Research Institute, for his offering the material and testing the chemical composition and mechanical properties of 316L and 420. 
Conflicts of Interest: The authors declare no conflict of interest.

\section{References}

1. Brennen, C.E. Hydrodynamics of Pumps; Jiangsu University Press: Zhenjiang, China, 2012; pp. 1-52.

2. Naudé, C.F.; Ellis, A.T. On the mechanism of cavitation damage by non-hemispherical cavities collapsing in contact with a solid boundary. J. Basic Eng. 1960, 83, 648-656. [CrossRef]

3. Dojcinovic, M.; Eric, O.; Rajnovic, D.; Sidjanin, L.; Balos, S. Effect of austempering temperature on cavitation behaviour of unalloyed ADI material. Mater. Charact. 2013, 82, 66-72. [CrossRef]

4. Zhen, L.; Han, J.; Lu, J.; Chen, J. Cavitation erosion behavior of Hastelloy C-276 nickel-based alloy. J. Alloy. Compd. 2015, 619, 754-759.

5. Kim, K.H.; Chahine, G.; Franc, J.P.; Karimi, A. Advanced Experimental and Numerical Techniques for Cavitation Erosion Prediction; Springer: New York, NY, USA, 2014.

6. Hattori, S.; Hirose, T.; Sugiyama, K. Prediction method for cavitation erosion based on measurement of bubble collapse impact loads. Wear 2009, 269, 507-514. [CrossRef]

7. Szkodo, M. Mathematical description and evaluation of cavitation erosion resistance of materials. J. Mater. Process. Tech. 2005, 164, 1631-1636. [CrossRef]

8. Hattori, S.; Maeda, K.; Zhang, Q. Formulation of cavitation erosion behavior based on logistic analysis. Wear 2004, 257, 1064-1070. [CrossRef]

9. Shuji, H.; Kohei, M. Logistic curve model of cavitation erosion progress in metallic materials. Wear 2010, 268, 855-862.

10. Wang, Y.; Stella, J.; Darut, G.; Poirier, T.; Liao, H.L.; Planche, M.P. APS prepared NiCrBSi-YSZ composite coatings for protection against cavitation erosion. J. Alloys Compd. 2017, 699, 1095-1103. [CrossRef]

11. Emelyanenko, A.M.; Shagieva, F.M.; Domantovsky, A.G.; Boinovich, L.B. Nanosecond laser micro- and nanotexturing for the design of a superhydrophobic coating robust against long-term contact with water, cavitation, and abrasion. Appl. Surf. Sci. 2015, 332, 513-517. [CrossRef]

12. Wang, Y.; Liu, J.W.; Kang, N.; Darut, G.; Poirier, T.; Stella, J.; Liao, H.L.; Planche, M.P. Cavitation erosion of plasma-sprayed CoMoCrSi coatings. Tribol. Int. 2016, 102, 429-435. [CrossRef]

13. Lin, J.R.; Wang, Z.H.; Lin, P.H.; Cheng, J.B.; Zhang, X.; Hong, S. Effects of post annealing on the microstructure, mechanical properties and cavitation erosion behavior of arc-sprayed FeNiCrBSiNbW coatings. Mater. Des. 2015, 65, 1035-1040. [CrossRef]

14. Kumar, A.; Sharma, A.; Goel, S.K. Effect of heat treatment on microstructure, mechanical properties and erosion resistance of cast 23-8-N nitronic steel. Mater. Sci. Eng. 2015, 637, 56-62. [CrossRef]

15. Wang, Z.; Zhu, J. Correlation of martensitic transformation and surface mechanical behavior with cavitation erosion resistance for some iron-based alloys. Wear 2004, 256, 1208-1213. [CrossRef]

16. Thiruvengadam, A.; Waring, S. Mechanical Properties of Metals and Their Cavitation Damage Resistance; Technical Report 233-5; Hydronautics Inc.: Laurel, MD, USA, 1 June 1964; p. 47.

17. Duraiselvam, M.; Galun, R.; Wesling, V.; Mordike, B.L.; Reiter, R.; Oligmüller, J. Cavitation erosion resistance of AISI 420 martensitic stainless steel laser-clad with nickel aluminide intermetallic composites and matrix composites with TiC reinforcement. Surf. Coat. Technol. 2006, 201, 1289-1295. [CrossRef]

18. Mottyll, S.; Skoda, R. Numerical 3D flow simulation of ultrasonic horns with attached cavitation structures and assessment of flow aggressiveness and cavitation erosion sensitive wall zones. Ultrason. Sonochem. 2016, 31, 570-589. [CrossRef]

19. Brennen, C.E. Cavitation and Bubble Dynamics; Oxford University Press: New York, NY, USA, 1995; pp. 71-85.

20. Schijve, J. Fatigue of Structures and Materials, 2nd ed.; Aviation Industry Press: Beijing, China, 2004; pp. 11-363.

21. Pędzich, Z.; Jasionowski, R.; Ziąbka, M. Cavitation wear of structural oxide ceramics and selected composite materials. J. Eur. Ceram. Soc. 2014, 34, 3351-3356. [CrossRef]

22. Choi, J.K.; Chahine, G.L. Relationship between material pitting and cavitation field impulsive pressures. Wear 2016, 352-353, 42-53. [CrossRef]

23. Hsu, K.L.; Gupta, H.V.; Sorooshian, S. Artificial neural network modeling of the rainfall-runoff process. Water Resour. Res. 1995, 31, 2517-2530. [CrossRef]

24. Jeyasehar, C.A.; Sumangala, K. Damage assessment of prestressed concrete beams using artificial neural network (ANN) approach. Comput. Struct. 2006, 84, 1709-1718. [CrossRef] 
25. Ye, L.; Su, Z.; Yang, C.; He, Z.; Wang, X. Hierarchical development of training database for artificial neural network-based damage identification. Compos. Struct. 2006, 76, 224-233. [CrossRef]

26. Zang, C.; Imregun, M. Structural damage detection using artificial neural networks and measured FRF data reduced via principal component projection. J. Sound Vib. 2001, 242, 813-827. [CrossRef]

27. Strdczkiewicz, M.; Barszcz, T. Application of artificial neural network for damage detection in planetary gearbox of wind turbine. Shock Vib. 2015, 2016, 1-12.

28. Xu, H.; Humar, J.M. Damage detection in a girder bridge by artificial neural network technique. Comput. Civ. Infrastruct. Eng. 2010, 21, 450-464. [CrossRef]

29. Altarazi, S.; Ammouri, M.; Hijazi, A. Artificial neural network modeling to evaluate polyvinylchloride composites' properties. Comput. Mater. Sci. 2018, 153, 1-9. [CrossRef]

30. Adoption, P.N. Centrifugal Pumps for Petroleum, Petrochemical and Natural Gas Industries; API Publishing Services: Washington, DC, USA, 2003.

31. Astm, N.G. Standard Test Method for Cavitation Erosion Using Vibratory Apparatus; ASTM: West Conshohocken, PA, USA, 2003.

32. Karimi, A.; Martin, J.L. Cavitation erosion of materials. Metall. Rev. 2013, 31, 1-26. [CrossRef]

33. Santa, J.F.; Blanco, J.A.; Giraldo, J.E. Cavitation erosion of martensitic and austenitic stainless steel welded coatings. Wear 2011, 271, 1445-1453. [CrossRef]

34. Xiaojun, Z.; Procopiak, L.A.J.; Souza, N.C.; D'Oliveira, A.S.C.M. Phase transformation during cavitation erosion of a Co stainless steel. Mater. Sci. Eng. A 2003, 358, 199-204. [CrossRef]

35. Li, D.G.; Wang, J.D.; Chen, D.R.; Liang, P. Ultrasonic cavitation erosion of Ti in $0.35 \% \mathrm{NaCl}$ solution with bubbling oxygen and nitrogen. Ultrason. Sonochem. 2015, 26, 99-110. [CrossRef]

36. Hugo, V.; De Albuquerque, C.; Tavares, M.R.S.; Durão, L.M.P.; João, P. Evaluation of Delamination Damage on Composite Plates using an Artificial Neural Network for the Radiographic Image Analysis. J. Compos. Mater. 2010, 44, 548-553.

37. Kůrková, V. Kolmogorov's theorem and multilayer neural networks. Neural Networks 1992, 5, 501-506. [CrossRef]

38. Singh, K.P.; Basant, A.; Malik, A.; Jain, G. Artificial neural network modeling of the river water quality-A case study. Ecol. Modell. 2009, 220, 888-895. [CrossRef]

39. Chen, M. Neural Network Principle and Example Elaboration of MATLAB; Tsinghua University Press: Beijing, China, 2003; pp. 21-157. 